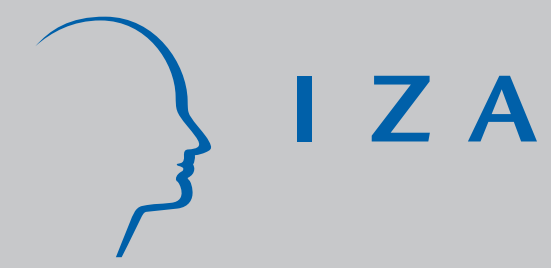

IZA DP No. 392

Identifying Population Groups at High Risk of Social Exclusion: Evidence from the ECHP

Panos Tsakloglou

Fotis Papadopoulos

November 2001 


\title{
Identifying Population Groups at High Risk of Social Exclusion: Evidence from the ECHP
}

\author{
Panos Tsakloglou \\ Athens University of Economics and Business, IMOP and IZA, Bonn \\ Fotis Papadopoulos \\ Athens University of Economics and Business
}

\author{
Discussion Paper No. 392 \\ November 2001
}

\author{
IZA \\ P.O. Box 7240 \\ D-53072 Bonn \\ Germany \\ Tel.: +49-228-3894-0 \\ Fax: +49-228-3894-210 \\ Email: iza@iza.org
}

This Discussion Paper is issued within the framework of IZA's research area The Welfare State and Labor Markets. Any opinions expressed here are those of the author(s) and not those of the institute. Research disseminated by IZA may include views on policy, but the institute itself takes no institutional policy positions.

The Institute for the Study of Labor (IZA) in Bonn is a local and virtual international research center and a place of communication between science, politics and business. IZA is an independent, nonprofit limited liability company (Gesellschaft mit beschränkter Haftung) supported by the Deutsche Post AG. The center is associated with the University of Bonn and offers a stimulating research environment through its research networks, research support, and visitors and doctoral programs. IZA engages in (i) original and internationally competitive research in all fields of labor economics, (ii) development of policy concepts, and (iii) dissemination of research results and concepts to the interested public. The current research program deals with (1) mobility and flexibility of labor markets, (2) internationalization of labor markets and European integration, (3) the welfare state and labor markets, (4) labor markets in transition, (5) the future of work, (6) project evaluation and (7) general labor economics.

IZA Discussion Papers often represent preliminary work and are circulated to encourage discussion. Citation of such a paper should account for its provisional character. 
IZA Discussion Paper No. 392

November 2001

\section{ABSTRACT}

\section{Identifying Population Groups at High Risk of Social Exclusion: Evidence from the ECHP}

In recent years in the public discourse of many European countries there has been a shift in emphasis from "poverty" to "social exclusion". Broadly interpreted, "social exclusion" implies the "inability of an individual to participate in the basic political, economic and social functionings of the society in which she/he lives". In practice, there is little consensus about its proper operationalisation.

The paper approaches "social exclusion" from the point of view of "chronic cumulative disadvantage" and attempts to identify population members at high risk of social exclusion in EU countries using the information of the European Community Household Panel (ECHP). The results show that there are many qualitative similarities and quantitative differences across the EU. In almost all countries the looser the links of the individual or the household with the labour market the higher the risk of social exclusion. However, the extent to which secure and uninterrupted employment provides a shield against social exclusion varies a lot across countries. Moreover, in almost all countries children face a higher risk of social exclusion than the rest of the population. To a large extent, this risk is accounted by the higher than average risk of social exclusion facing children living in lone-parent households. On the contrary, older persons face a high risk of social exclusion in only a few southern EU countries.

JEL Classification: I30, I31

Keywords: $\quad$ Social exclusion, European Union, household survey

Panos Tsakloglou

Department of International and European Economic Studies

Athens University of Economics and Business

76 Patission Street

Athens 10434

Greece

Tel.: +3018203195

Fax: +3018214122

Email:panos@aueb.gr 


\section{Introduction}

In recent years in the public discourse of many European countries there has been a shift in emphasis from 'poverty' to 'social exclusion', a term first used in France in the 1970s by Lenoir (1974). Broadly interpreted, 'social exclusion' implies the 'inability of an individual to participate in the basic political, economic and social functionings of the society in which he or she lives'. In practice, it has been given several interpretations by social scientists and policy-makers alike such as 'exclusion from the labour market', 'acute poverty and material deprivation', 'inability to exercise basic social rights' etc. $\square_{\text {and }}$, until now, there does not seem to be a general consensus about its proper operationalisation. As Atkinson (1998) points out, at least part of the concept's popularity, especially among policy-makers, should be attributed to its vagueness.

The present paper aims to provide an example of a methodology for the identification of population members at high risk of social exclusion using the data of the European Community Household Panel (ECHP). Then, using this evidence, we highlight similarities and differences across EU member states regarding population groups at high risk of social exclusion. The remainder of the paper is organised as follows: Section 2 provides a brief outline of the views of some important thinkers about meaning of 'social exclusion'; Section 3 briefly discusses the data used in the paper; Section 4 deals with methodological issues, Section 5 provides the bulk of the empirical analysis and Section 6 concludes the paper.

\section{The Concept of Social Exclusion}

Earlier views on the distinction between the concepts of 'social exclusion' and 'poverty' tended to stress two points. Firstly, that 'poverty' is unidimensional since it is concerned exclusively with the lack of material resources (mainly income), whereas 'social exclusion' is multidimensional since it is related to a broad range of aspects of deprivation. Secondly, that 'poverty' is a static concept, whereas 'social exclusion' is a dynamic concept. Both points are controversial. Many social scientists have argued that poverty is a multidimensional phenomenon and several of them have incorporated aspects of multiple deprivation in their analyses - even though a

\footnotetext{
${ }^{1}$ For a comprehensive survey of the various uses of the concept of 'social exclusion' in a number of European countries and contexts, see Mayes et al. (2001) and, especially, the chapter by Vleminckx and Berghman (2001).

2 See Berghman (1995) and the references cited there.
} 
considerable proportion among them (mostly, but not exclusively, economists) just pay lip services to the multidimensional character of poverty and perform their

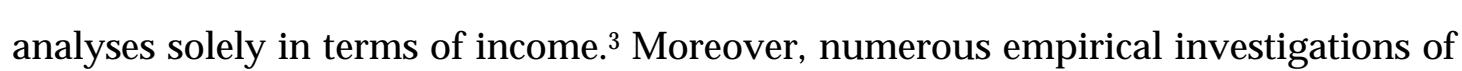

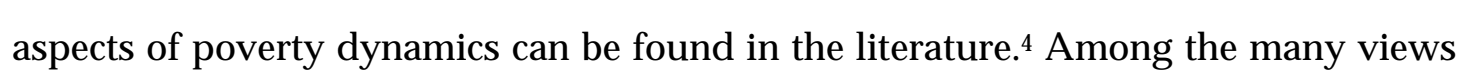
expressed on the meaning of 'social exclusion' in recent years, we summarise three characteristic ones below.

Following Room (1995), who has been very influential in the conceptualisation of the term in the EU, social exclusion is characterised by five key factors: (1) It is multidimensional, in the sense that it is not only concerned with income, but also with a wide range of indicators of living standards. (2) It is dynamic, in the sense that analysing social exclusion means understanding a process and identifying the factors that can trigger entry into or exit from it. (3) It has a neighbourhood dimension, in the sense that multiple deprivation is caused not only by lack of personal resources but also by insufficient or unsatisfactory community resources. (4) It is relational, in the sense that it implies inadequate social participation, lack of social integration and lack of power. (5) It implies a major discontinuity in the relationship of the individual with the rest of society.

In his 1998 IARIW Conference plenary lecture, Sen (1998) argued that social exclusion is wider than poverty. Unlike poverty, social exclusion is better defined in the space of capabilities rather than the space of commodities (or income) and can be viewed both as a state and as a process leading to deprivation. Further, according to Sen, its quantification calls for discriminant treatment in areas suchas unemployment, lack of access to healthcare, lack of educational opportunities, absence of social safety nets, credit market exclusion, lack of facilities for disabled persons, marketing limitations, political exclusion and cultural exclusion.

According to Atkinson (1998), social exclusion is characterised by three main elements: (i) Relativity: it implies exclusion from a particular society at a particular time. In other words, unlike poverty, we cannot talk about 'absolute' and 'relative' social exclusion. (ii) Agency: it lies beyond the narrow responsibility of the individual concerned. (iii) Dynamics: it has serious dynamic implications in the sense

3 The pioneering work that highlighted the multidimensional nature of poverty is probably that of Townsend (1979). For an interesting operationalisation by economists, see Desai and Shah (1988).

${ }^{4}$ See, for example, Jenkins (2000) and the references cited there. 
that people are excluded not just because of their current situation, but also because they have little prospects for the future.

\section{D ata}

Undoubtedly, the data requirements for the operationalisation of the three approaches outlined above - especially Sen's - are daunting and, almost certainly, the information required for their full implementation does not exist in any data set currently available. In the next section we attempt to provide an operational approximation to the approaches using the information that is currently available in the ECHP; that is, the first three waves of the panel, which cover the period 1994-96. The ECHP is an ambitious effort to collect information on the living standards of the households of the EU member states using common definitions, information collection methods and editing procedures. It contains detailed information on incomes, socio-economic characteristics, housing amenities, consumer durables, social relations, employment conditions, health status, subjective evaluation of wellbeing etc.

One of the main objectives of the ECHP is, precisely, the collection of data that could be used for the exploration of various aspects of social exclusion. N evertheless, in many cases, the information collected refers to 'functionings' rather than 'capabilities', which could be considered as more appropriate for the investigation of aspects of social exclusion (Sen, 1999). Moreover, using the information of the ECHP it is not possible to examine in depth a number of the aforementioned aspects of social exclusion (for example, agency, neighbourhood dimensions, social safety nets etc.).

Of the 15 EU member states, Sweden is not currently participating in the ECHP, while Austria and Finland joined after the first wave. Since the main body of our analysis is based on the use of the data of all three ECHP waves currently available, estimates for Austria and Finland are reported only when static indicators of deprivation and cumulative disadvantages are presented, while for the analysis of social exclusion wehad to restrict our study to 12 countries only.

${ }^{5}$ Details of the methodology used for the collection of information in the ECHP can be found in EUROSTAT (1996). For issues related to the quality of the information collected, see EUROSTAT (1999). 


\section{M ethodological issues}

The general approach of the paper is the following: first, using the information of the ECHP, we construct static indicators of deprivation in particular fields. In the second stage, we 'aggregate' this information in order to derive a static indicator of cumulative disadvantage. In the final stage, we focus on chronic cumulative disadvantage, which can be considered as a reasonable approximation to the concept of 'social exclusion' as outlined above. Throughout the paper, the unit of analysis is the individual (population member), although most of the information used has been collected at the household level.

\subsection{D eprivation}

Of the various blocks of information available in the ECHP, we selected four in order to proceed to the construction of deprivation indicators in particular fields: Income (Poverty), Living Conditions, Necessities of Life and Social Relations. The ECHP contains information on a number of other fields that, under different circumstances, could be fruitfully exploited for the purposes of the identification of population members at high risk of exclusion (such as current health status, highest education level attained, indebtedness, social security coverage etc.). This information is not used here for various reasons (quality of information, cross-country comparability, information related to outcomes rather than ability to participate etc.). Moreover, no indicators of labour market exclusion are included among the deprivation indicators for two reasons. This is because, firstly, if labour market status is included among the indicators of exclusion, a considerable proportion of the population that cannot participate in the labour market is left out of the analysis (including some vulnerable groups such as the elderly, the disabled, etc.). Secondly, using the information available we run the risk of confusing the cause (adverse employment history) with the outcome (exclusion)

\subsubsection{Poverty}

The income information available in the ECHP includes only monetary incomes - i.e., it does not contain information on incomes in-kind from either private or public

${ }^{6} \mathrm{M}$ oreover, as the empirical results that are reported below demonstrate, in a number of EU countries a considerable proportion of the unemployed and/ or precariously employed do not seem to enjoy a particularly low standard of living and/ or suffer from inadequate social relations. 
sources - and, hence, may be regarded as a not entirely satisfactory approximation of the concept of 'command over resources'. There are two concepts of disposable monetary income available in the ECHP. The first is 'net income from all sources during the previous year'. The second is 'current net monthly income'. The former is more comprehensive and, ceteris paribus, more appropriate for empirical poverty analyses. The latter is less accurate, but has two very serious advantages in the framework of the present study. The first advantage is that it is contemporaneous with the employment or family status of the population member. The second, and perhaps more important in the present context, is that using this concept of income we are able to exploit the information of all three waves of the ECHP. This is very important in view of the fact that we wish to explore dynamic aspects of social exclusion and using the former concept we would only be able to use information for two instead of three years. Therefore, we decided to use 'current net monthly income' in our analysis. In line with the current practice of the EU, the poverty line is set at $60 \%$ of the median equivalent income per capita, using the 'modified OECD equivalence scales' (Hagenaars et al.,1994).

Application of this methodology to the data of the most recent (third) wave of the ECHP produces the results reported in the first column of Table 1. These estimates are not substantially different than those reported in EU publications (EUROSTAT, 1997, M ejer, 1999) and show that, as anticipated, relative poverty tends to be higher in countries with higher levels of aggregate inequality such as the Southern European countries and the UK, and lower in the low inequality countries of Northern and Central Europe.

\footnotetext{
7 The evidence of Smeeding et al. (1993) suggests that the inclusion of non-cash public transfers in the concept of income results in a reduction in the measured levels of inequality and poverty in a number of northern and central European countries. Likewise, Rodrigues (1999) and Tsakloglou and Papadopoulos (2001) report that the omission of private incomes in-kind increases the recorded levels of inequality and poverty in Portugal and Greece substantially. Nonetheless, a very considerable proportion of empirical poverty studies utilise distributions of disposable monetary income, especially EU-supported studies; (see, for example, O'Higgins and Jenkins, 1990; ISSA S, 1990; Hagenaars et al., 1994.

8 It should be noted that the results we derived when we replaced 'current net monthly income' by 'net income from all sources during the previous year' and restricted the analysis to two years were only marginally different from the results reported in the next section.

${ }^{9}$ Our analysis is based on the head count ratio - i.e. the proportion of the population falling below the selected cut-off threshold - thus, ignoring the distance of the poor population member from this threshold (poverty gap). The same applies to the remaining indicators of deprivation used in this paper. The construction of deprivation indicators based on gaps as well as head counts would have complicated substantially the next step of the analysis (aggregation) and is left for further investigation in the future.
} 
Table 1 Aggregate deprivation indicators

\begin{tabular}{lllll}
\hline \multirow{3}{*}{ Country } & \multicolumn{4}{l}{$\begin{array}{l}\text { Proportion of the population in the 3rd wave of } \\
\text { theECHP classified as deprived according to: }\end{array}$} \\
\cline { 2 - 5 } & $\begin{array}{l}\text { Income } \\
\text { (poverty) }\end{array}$ & $\begin{array}{l}\text { Living } \\
\text { conditions }\end{array}$ & $\begin{array}{l}\text { Necessities } \\
\text { of life }\end{array}$ & $\begin{array}{l}\text { Social } \\
\text { relations }\end{array}$ \\
\hline Austria & 11.0 & 6.8 & 11.3 & 5.7 \\
Belgium & 13.3 & 7.6 & 11.1 & 8.5 \\
Denmark & 12.8 & 3.4 & 5.7 & 3.4 \\
Finland & 13.9 & 4.0 & 12.3 & 2.9 \\
France & 17.6 & 6.9 & 14.3 & 4.3 \\
Germany & 9.9 & 5.6 & 10.7 & 4.3 \\
Greece & 20.7 & 9.8 & 31.8 & 2.1 \\
Ireland & 15.0 & 10.0 & 15.5 & 0.7 \\
Italy & 15.8 & 8.6 & 15.0 & 6.6 \\
Luxembourg & 11.3 & 4.8 & 7.5 & 6.4 \\
Netherlands & 11.3 & 3.8 & 9.7 & 5.2 \\
Portugal & 23.2 & 20.6 & 15.3 & 4.7 \\
Spain & 18.8 & 7.6 & 15.5 & 2.3 \\
UK & 22.3 & 5.4 & 17.7 & 1.8 \\
\hline
\end{tabular}

\subsubsection{Living conditions}

In the field of Living Conditions, the ECHP contains information on 22 items covering the availability of certain household amenities, the existence of particular problems in the accommodation and the enforced lack of a number of durable goods. Detailed description of the relevant information can be found in Appendix 1 . These amenities/problems/durables are not equally important in all countries. For example, possessing a dishwasher may be very common in country $A$, but less common in country $B$. Therefore, in order to aggregate the available information into a single 'welfare indicator' in the field of Living Conditions, for every item under consideration we assigned to each population member living in a particular country and having access to a particular housing amenity or lack of problem or durable good, a weight equal to the proportion of the country's population living in dwellings not lacking the corresponding amenity or not reporting the relevant problem or not reporting enforced lack of the particular durable good.

As a result, for instance, if a particular durable good is very rare (common) in a particular country, an individual living in a household with such a durable good is assigned a low (high) welfare weight. Then, the weights of each person are added and the resulting sum is divided by the sum of the average 'welfare scores' for each 
item for the entire population (that is, the sum of the proportions of the population not lacking particular housing amenities or not reporting particular housing problems or having particular items).

In algebraic terms, the formula for the calculation of each person's 'welfare indicator', $u_{j}$, is

$$
u_{j}=\frac{\sum_{i=1}^{I} w_{i} X_{i j}}{\sum_{i=1}^{I} w_{i}}
$$

where $I$ is the total number of amenities/ (lack of) problems/ durables for which information is available ( 22 items), $w_{i}$ is the proportion of the country's population living in accommodation with amenity $i$, or without reporting problems with item $i$, or not reporting enforced lack of durable good $i$ and $X_{i j}$ a variable that takes the value of $1(0)$ if individual $j$ lives in a household that is (is not) equipped with amenity $i$ or does not (does) report problems with item $i$ or does not (does) report enforced lack of durable good $i$. For each population member the 'welfare indicator', $u_{j}$, takes values between 0 (complete deprivation) and 1 (no deprivation). In the next step, we select a particular cut-off point in the distribution of the above welfare indicator and define as persons at high risk of deprivation in the field of Living Conditions those individuals that fall below this threshold. For the purposes of our analysis, we selected a cut-off point equal to $80 \%$ of the median of the distribution of the above welfare indicator.

Using this methodology on the data of the third wave of the ECHP produces the results reported in the second column of Table 1 . This time the cross-country differences are substantially larger than the differences reported in the first column of the table. Even though there is a negative correlation between the share of a country's population classified as deprived in the field of Living Conditions and the average living standards of the corresponding countries, it should be kept in mind that these scores are purely relative, in the sense that they have been derived using national cut-off points.

${ }^{10}$ See Tsakloglou and Papadopoulos (2001). 


\subsubsection{N ecessities of life}

In the field of Necessities of Life, the households that participated in the ECHP were asked a few questions about their ability to afford (if they wanted to) a number of activities considered to be quite basic. Detailed description of the relevant information can be found in Appendix I. The methodology we used for the construction of a deprivation indicator in the field of Necessities of Life is similar to that outlined above for the construction of a deprivation indicator in the field of Living Conditions. We first constructed country-specific welfare indicators for each population member based on the proportion of the country's population that lives in households where the reference person replied positively to each of the questions asked. Then, we selected a cut-off point equal to $60 \%$ of the national median Following this methodology, we derived the estimates reported in the third column of Table 1 .

\subsubsection{Social Relations}

Finally, for the purposes of the construction of a deprivation indicator in the field of inadequate Social Relations, we classified as deprived those population members aged 16 or more who reported that they talk to their neighbours 'once or twice a month' or less frequently and, in addition, they meet friends 'once or twice a month' or less frequently and they are not members of a club or organisation (such as a sport or entertainment club, a local or neighbourhood group, a political party, etc.). In the case of children aged below 16 we classified them as deprived or non-deprived in

\footnotetext{
${ }^{11} \mathrm{~N}$ aturally, the cut-off points used in such studies are quite arbitrary. Initially, for reasons of symmetry with the cut-off point selected in the field of 'living conditions', we considered a cut-off point equal to $80 \%$ of the median welfare score in the field of 'necessities of life'. However, using this threshold in some countries, such as Portugal, over $40 \%$ of the population was classified as being at high risk of deprivation. Since we consider 'deprivation' to be a rather strong term, we decided to adopt a lower threshold that would enable us to identify those at a relatively severe risk of deprivation in the field of 'necessities of life' in the member states of the EU.

${ }^{12}$ As noted earlier, since the distributions and the cut-off points used for the derivation of these estimates are country-specific, they should not be interpreted as (inverse) proxies of the countries' living standards. Moreover, national idiosyncrasies and/ or translation of the relevant question in the national questionnaire may have influenced these estimates. For example, in Greece around $18 \%$ of the households replied negatively to all the questions (reported in the relevant section of A ppendix I), even though some of them belonged to the top decile of the distribution of equivalent income.
} 
this field in accordance with the classification of the reference person of their households. The corresponding estimates are reported in the last column of Table 1.3

Unlike the other two non-monetary deprivation indicators that are likely, at least to some extent, to be correlated with the financial conditions of the individual and his/ her household, this indicator aims to capture non-material aspects of exclusion. Certainly, an individual classified as deprived in the field of Social Relations according to the above definition must live a very isolated life, even if he or she has the ability to sustain a relatively high material standard of living. An attempt to examine the extent of the overlap between monetary deprivation (poverty) and deprivation in the fields of Living Conditions, Necessities of Life and Social Relations is presented in Table 2. According to the estimates reported there, on average, a little

Table 2 Overlapping of Monetary and N on-monetary Deprivation Indicators

\begin{tabular}{lccl}
\hline \multirow{2}{*}{$\begin{array}{l}\text { Country } \\
\text { Croportion of those classified }\end{array}$} & $\begin{array}{l}\text { as deprived } \\
\text { according to one of the following criteria, falling } \\
\text { below the poverty line: }\end{array}$ \\
\hline & $\begin{array}{l}\text { Living } \\
\text { Conditions }\end{array}$ & $\begin{array}{l}\text { Necessities of } \\
\text { Life }\end{array}$ & $\begin{array}{l}\text { Social } \\
\text { Relations }\end{array}$ \\
\hline Austria & 26.0 & 28.1 & 17.5 \\
Belgium & 32.7 & 37.3 & 16.4 \\
Denmark & 33.9 & 35.1 & 26.2 \\
Finland & 33.7 & 30.1 & 17.9 \\
France & 43.6 & 47.8 & 30.0 \\
Germany & 34.8 & 38.1 & 16.5 \\
Greece & 47.7 & 41.3 & 21.6 \\
Ireland & 44.6 & 40.0 & $(6.9)$ \\
Italy & 40.2 & 36.4 & 19.7 \\
Luxembourg & 27.9 & 35.9 & $(14.3)$ \\
Netherlands & 34.8 & 44.3 & 14.7 \\
Portugal & 43.9 & 48.4 & 19.6 \\
Spain & 41.2 & 45.2 & 15.3 \\
UK & 62.3 & 64.6 & 25.7 \\
\hline
\end{tabular}

$N$ ote: Figures in parentheses denote that the estimate was derived from a small number of observations (between 20 and 50 ).

\footnotetext{
13 In this case, too, national idiosyncrasies and/ or translation of the relevant question in the national questionnaires may have influenced the estimates reported in Table 1. N ote al so that the wording of the French questionnaire was slightly different from that used in the rest of the countries.

${ }^{14} \mathrm{H}$ owever, using the existing information we cannot be certain whether the individual chose to be in this state (unlikely but not impossible) or not.
} 
over $40 \%$ of those classified as deprived in the fields of Living Conditions and Necessities of Life were also falling below the poverty line. The corresponding figure for those dassified as deprived in the field of Social Relations is, on average, below $20 \%$.

\subsection{Cumulative D isadvantage}

Once the static deprivation indicators for each population member were calculated, we wanted to proceed to the examination of their 'cumulative disadvantage', i.e. the extent to which they were classified as deprived according to the above criteria. One way to proceed is to look for 'dominance effects'; that is, the extent to which some population members are classified as deprived according to all four criteria used here. It turns out that in all countries only a tiny fraction of the population belongs to this group. 15 nother approach is to look at the number of criteria according to which each population member is classified as deprived and draw a line at a certain threshold. An example of the latter approach using the data of the third wave of the ECHP is presented in Table 3.

Table 3 Aggregate indicators of cumulative disadvantage

\begin{tabular}{|c|c|c|c|c|c|}
\hline \multirow[t]{2}{*}{ Country } & \multicolumn{5}{|c|}{$\begin{array}{l}\text { Proportion of the population in the 3rd wave of the } \\
\text { ECHP classified as deprived according to:* }\end{array}$} \\
\hline & $\begin{array}{l}\text { No } \\
\text { criterion }\end{array}$ & $\begin{array}{l}\text { At least } \\
\text { one } \\
\text { criterion }\end{array}$ & $\begin{array}{l}\text { At least } \\
\text { two } \\
\text { criteria }\end{array}$ & $\begin{array}{l}\text { At least } \\
\text { three } \\
\text { criteria }\end{array}$ & $\begin{array}{l}\text { All four } \\
\text { criteria }\end{array}$ \\
\hline Austria & 73.5 & 26.5 & 6.6 & 1.4 & ** \\
\hline Denmark & 80.1 & 19.9 & 3.9 & (0.6) & ** \\
\hline Finland & 74.4 & 25.6 & 6.1 & 1.1 & ** \\
\hline France & 70.2 & 29.8 & 10.1 & 2.7 & $(0.3)$ \\
\hline Germany & 78.3 & 21.7 & 6.5 & 1.8 & ** \\
\hline Greece & 57.1 & 42.9 & 17.2 & 4.4 & ** \\
\hline Ireland & 73.0 & 27.0 & 9.9 & 3.8 & $* *$ \\
\hline Italy & 67.7 & 32.3 & 10.1 & 3.0 & 0.3 \\
\hline Luxembourg & 76.6 & 23.4 & 5.6 & (0.9) & $* *$ \\
\hline Netherlands & 78.3 & 21.7 & 5.6 & 1.1 & $* *$ \\
\hline Portugal & 58.0 & 42.0 & 15.8 & 5.4 & 0.4 \\
\hline Spain & 68.2 & 31.8 & 9.9 & 2.3 & ** \\
\hline UK & 68.1 & 31.9 & 13.5 & 3.3 & ** \\
\hline
\end{tabular}

N ote: * See the criteria used in Table 1 ** denotes that there were fewer than 20 observations, whereas figures in parentheses denote that the estimate was derived from a small number of observations (between 20 and 50).

15 For similar evidence for the UK using an alternative methodology, see Burchardt et al. (1999). 
Even though, for the reasons outlined above, these estimates may not be strictly comparable across countries, the figures reported in the first column of Table 3 suggest that in all countries the majority of the population is not classified as deprived according to any of the criteria used in our analysis. Between $20 \%$ (Denmark) and 43\% (Greece) are classified as deprived according to at least one criterion, while considerably fewer are classified as deprived according to at least two criteria. The share of the population classified as deprived according to three or four criteria varies between $5.4 \%$ (Portugal) and less than 1\% (Denmark and Luxembourg). Where should we draw the line, then? Certainly, being classified as deprived according to one criterion only may be due to a chance factor. In addition, at least one of the criteria used - inadequate social relations - may not be considered alone to provide sufficient evidence of exclusion. On the contrary, limiting the group of people at high risk of cumulative disadvantage to those classified as deprived according to three or four criteria would, in most cases, restrict the group to an extremely small group of 'seriously disadvantaged' persons and would not allow any further analysis of the group's characteristics. Taking these factors into account, we decided to consider as persons at high risk of (static) cumulative disadvantage, those that are classified as deprived according to at least two of the above deprivation indicators. Using this criterion, the population share of the group varies between 3.9\% (Denmark) and 17.2\% (Greece). High shares are also recorded in Portugal, the UK, France, Italy, Ireland and Spain, whereas the corresponding shares in Luxembourg, the Netherlands, Finland, Germany, A ustria and, to a lesser extent, Belgium are relatively low.

\subsection{Social Exclusion}

As noted in section 2, one of the characteristics of social exclusion that has been emphasised in the literature is its dynamic nature. Being excluded today may give you little prospect of escaping exclusion in the future. It is this dynamic aspect that we are focusing upon in this section. Table 4 subdivides each country's population according to the number of times (years) they were classified as being at high risk of cumulative disadvantage during a period of three years using the data of the balanced sample of the first three waves of the ECHP.

16 In the case of almost half of the Belgian households in the second wave of the ECHP it was not possible to identify the reference person and we had to reconstruct the variable using 
Table 4 Aggregate indicators of high risk of 'social exclusion'

\begin{tabular}{lllll}
\hline Country & \multicolumn{2}{l}{$\begin{array}{l}\text { Proportion of the population } \\
\text { suffering from cumulative disadvantage during a } \\
\text { period of three years:* }\end{array}$} \\
& Never & $\begin{array}{l}\text { At least } \\
\text { once }\end{array}$ & $\begin{array}{l}\text { At least } \\
\text { twice }\end{array}$ & Three times \\
\hline Belgium & 85.3 & 14.7 & 7.3 & 3.0 \\
Denmark & 92.3 & 7.7 & 2.9 & $(0.7)$ \\
France & 83.8 & 16.2 & 8.4 & 3.7 \\
Germany & 87.9 & 12.1 & 5.2 & 2.0 \\
Greece & 71.9 & 28.1 & 15.3 & 8.0 \\
Ireland & 85.1 & 14.9 & 7.9 & 3.4 \\
Italy & 81.1 & 18.9 & 9.5 & 4.4 \\
Luxembourg & 88.2 & 11.8 & 5.1 & $(1.9)$ \\
Netherlands & 90.4 & 9.6 & 4.3 & 2.1 \\
Portugal & 72.9 & 27.1 & 16.7 & 9.7 \\
Spain & 80.5 & 19.5 & 8.3 & 3.2 \\
UK & 78.4 & 21.6 & 13.2 & 7.2 \\
\hline
\end{tabular}

$N$ ote: * See the criteria used in Table 6.1, figures in parenthesis denote that the estimate was derived from a small number of observations (between 20 and 50).

As could be expected, considering the evidence of the previous tables, in all countries the great majority of the population is not classified as being at high risk of cumulative disadvantage in any of the three years under consideration. The share of those classified as being at high risk of cumulative disadvantage in at least one year varies substantially across countries; from $7.7 \%$ in Denmark to $28.1 \%$ in Greece. At the other extreme, considerable variation is also observed with respect to the population share of those classified as being at high risk of cumulative disadvantage during all three years; from less than $1 \%$ in Denmark to almost $10 \%$ in Portugal. We would argue that being at high risk of cumulative disadvantage only once during a period of three years may be attributed to a chance factor and does not provide a strong indication of high risk of social exclusion. Likewise, escaping a high risk of cumulative disadvantage only once in three years may also be attributed to a chance factor and should not be considered as a strong indication of low risk of social exclusion. Therefore, we decided to focus on those classified as being at high risk of cumulative disadvantage at least twice during a period of three years and classify them as being at high risk of social exclusion. The corresponding estimates are 
reported in the third column of Table 4. They show that the cross-country variation is quite significant. Only $2.7 \%$ of the Danish population is classified as being at high risk of social exclusion, whereas the corresponding proportion for Portugal is $16.7 \%$. High scores are also recorded in Greece (15.3\%) and the UK (13.2\%) and relatively low ones in the Netherlands (4.3\%), Luxembourg (5.1\%) and Germany (5.2\%). For the rest of the countries under consideration the relevant share varies between $6.8 \%$ and $9.5 \%$

\section{Population Groups at High Risk of Social Exclusion}

The aim of this section is to identify population groups at exceptionally high (or low) risk of social exclusion in the EU countries included in our analysis and highlight cross-country similarities and differences. As some of the views reported in section 2 imply, it might not be completely uncontroversial to perform cross-country comparisons of levels of social exclusion. On the contrary, it is far less controversial to analyse the relative risks of social exclusion of particular population groups vis-àvis the risks of the entire population within individual countries.

For the purposes of our analysis, each country's population (balanced sample) is subdivided according to four criteria. These criteria refer to an individual's characteristics in the first wave of the ECHP. They are: employment status of the household's reference person, household type, age group and employment situation of the individual. 18 For the purposes of our analysis we present three types of estimates. The first is the relative risk of social exclusion of the population group in comparison with the national average. Figures substantially higher (lower) than 1 indicate a high (low) risk of social exclusion in comparison with the rest of the population within a particular country. However, two identical relative risk factors may represent very different population shares at high risk of social exclusion, depending on the country's aggregate population share at high risk of social

17 The operationalisation adopted in this paper interprets 'social exclusion' as 'chronic cumulative disadvantage'. However, according to an alternative view, social exclusion is primarily associated with a number of characteristics of the 'excluded' persons rather than their material conditions of living. For example, in many EU member-states the Roma (gypsies) may be considered as excluded from the rest of the society, even though several members of the group may not be classified as deprived according to the criteria used here. Due to data and other limitations, this aspect of social exclusion is missing from our analysis. 18 The same analysis was also performed using as grouping factors the individual's characteristics throughout the three waves of the ECHP, adding an extra category labelled 'changed status' to the categories reported below. Reference to these estimates - which are 
exclusion For this reason, we also report the proportions of each group's members that are considered to be at high risk of social exclusion. In Graphs 1.1-1.5, 2.1-2.5, 3.1-3.5 and 4.1-4. 6 we report the group's relative risk factor (grey bar) and the proportion of the group classified as being at high risk of social exclusion (black bullet). In many countries several small population groups may be classified as being at a very high risk of social exclusion but their contribution to aggregate social exclusion may be quite low. For this reason, Graphs 1.6, 2.6, 3.6 and 4.7 are devoted to the examination of the composition of the group of persons that are classified as being at high risk of social exclusion in each country.

\subsection{Risk of social exclusion according to the employment status of the reference person}

Graphs 1.1-1.5 present evidence on the risk of social exclusion of population groups formed according to the status of the household's reference person in wave 1 , whereas Graph 1.6 reports the corresponding composition of those classified as being at high risk of social exclusion. Graph 1.1 reports estimates for population members living in households where the reference person in wave 1 was employed full-time (30 hours per week or more, using EUROSTAT'S definition). In both the traditional 'bread-winner' models and in much of the public discourse, employment, especially full-time employment, is considered the safest barrier against poverty and social exclusion. The evidence of Graph 1.1 is, broadly, in line with this assertion. In all countries, the risk of social exclusion of this population group is lower than that of the national average. However, some interesting cross-country differences emerge as well. In some countries, such as the UK and Ireland, the relative risk factor of the group is very low, whereas in other countries, such as Luxembourg, Portugal and Italy, the group's risk of social exclusion is not dramatically lower than that of the entire population. In fact, in Portugal $12.5 \%$ of the group's members are classified as being at high risk of social exclusion. Taking into account that in all countries the

not reported here but are available from the authors on request - is made in the paper.

19 For example, using the evidence reported below, the relative risk factor of members of lone parent households in the N etherlands is 6.52, whereas the corresponding figure in Portugal is only 1.40. Nonetheless, since the population share of persons classified as being at high risk of social exclusion in the Netherlands is $4.3 \%$ and in Portugal $16.7 \%$, the shares of members of lone parent households at high risk of social exclusion in the two countries do not differ substantially (28.1\% in the Netherlands against $23.4 \%$ in Portugal). In fact, given the national figure for Portugal, it is not possible for the Portuguese group to reach the risk factor of their Dutch counterparts (it would require 109\% of the group's members to be classified as being at high risk of exclusion!). 
group's population share is very large (between $63 \%$ and $78 \%$ ) it is not surprising to find that a very considerable proportion of those classified as being at high risk of social exclusion are members of the group. The evidence of Graph 1.6 shows that in seven of the countries under consideration (Luxembourg, Portugal, Italy, Greece, Germany, France and Belgium) the group's contribution is the highest among all groups when the population is grouped according to the employment status of the reference person in wave 1 . In the first three of these countries, more than half of the persons considered to be at high risk of social exclusion belong to this group. Naturally, several members of the group who were living in households whose reference person was employed full-time in wave 1, were living in different household types in waves 2 and 3 . If we restrict our attention to population members living in households whose reference persons were employed full time throughout the period under consideration (3 waves), the group's relative risk factors decline substantially in all countries, thus, giving further support to the view that stable fulltime employment of the household head may be an effective barrier against social exclusion.

Graphs 1.1-1.5. Population Members at High Risk of Social Exclusion (Groups formed according to the employment status of the household head in wave 1)

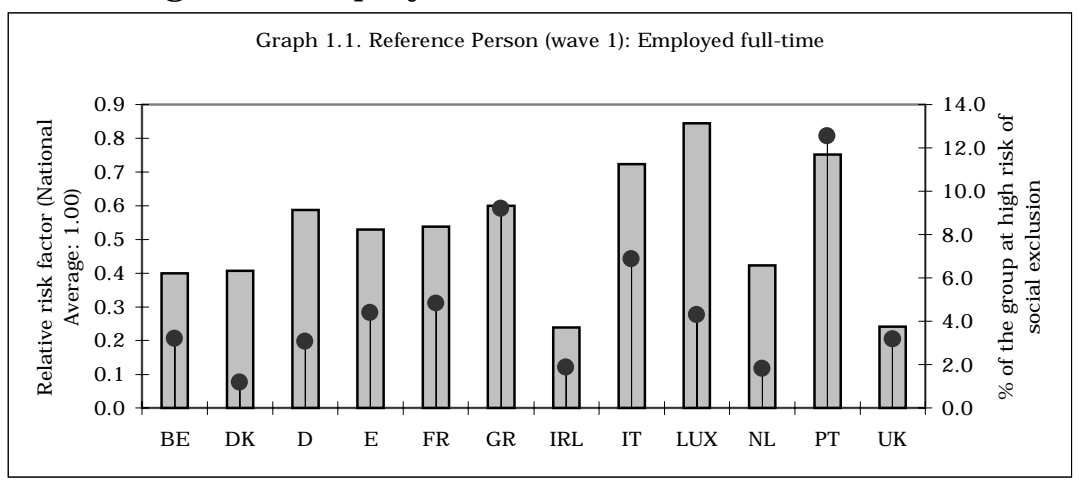

\footnotetext{
20 In this case, both the group's population share and contribution to aggregate risk of social exclusion decline, on average, by about 15 percentage points and in all but one of the countries under examination (Luxembourg) the group of persons living in households whose reference person changed employment status during the first three waves of the ECHP becomes the single most important contributor to the group of persons at high risk of social exclusion.
} 

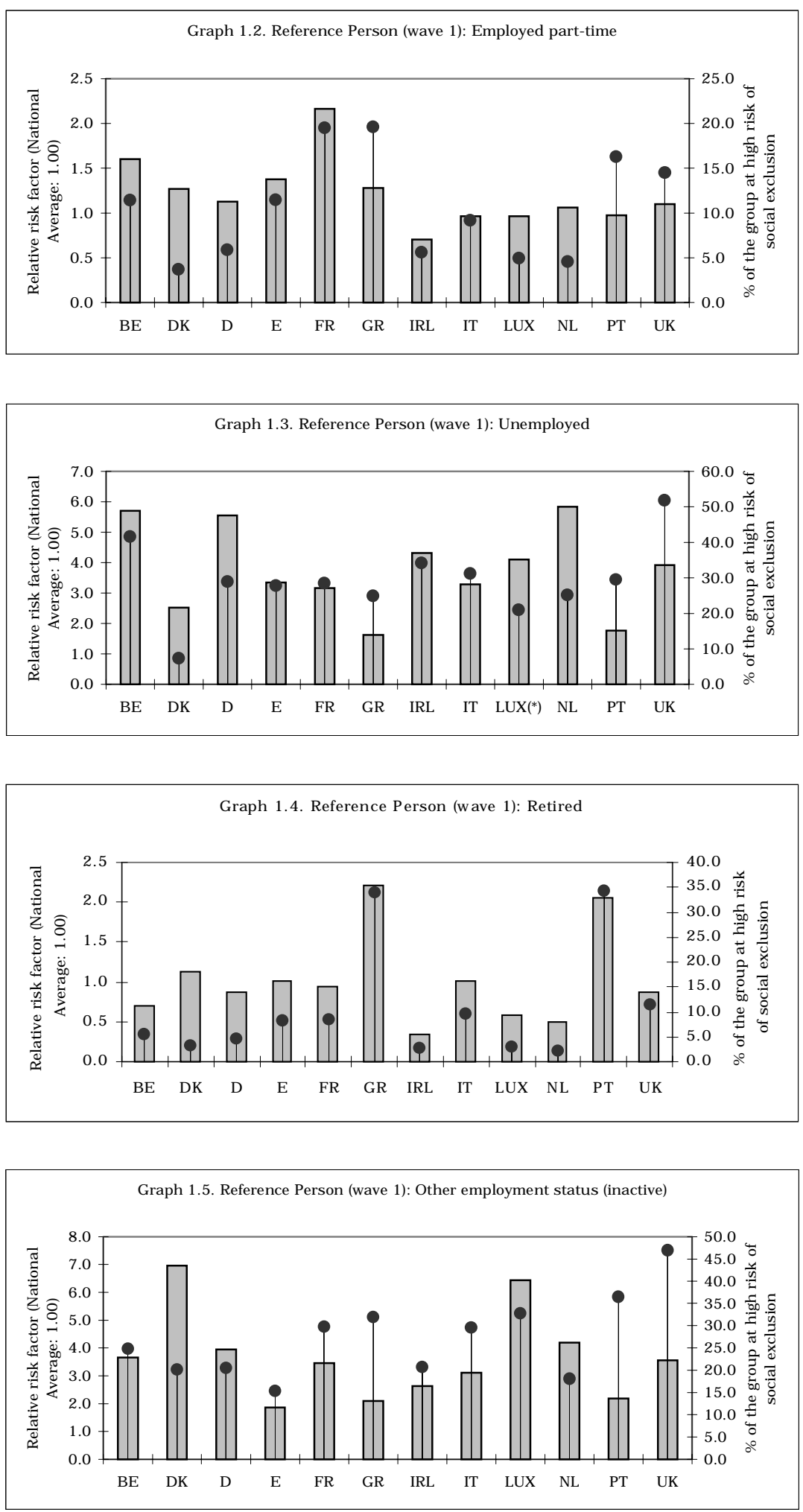
Graph 1.6 Composition of the group of persons at high risk of social exclusion

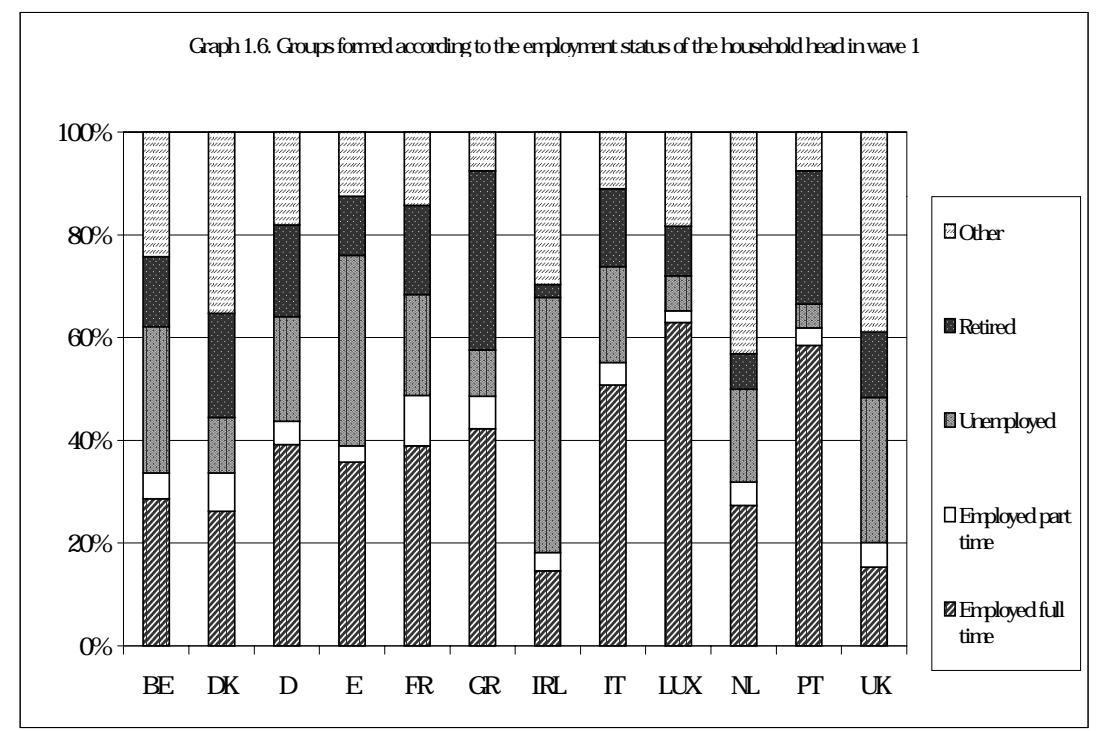

Graph 1.2 presents similar evidence for the members of households whose reference person in wave 1 was employed part-time (less than 30 hours a week). In many European countries most of the part-time workers are not household heads and, in fact, in most countries relatively few of this group's members remained members of the group throughout the period under examination. For this reason, below we examine separately the relative risks of the group of all part-time workers, irrespective of their relationship with the reference person. The evidence of Graph 1.2 shows that in most countries under examination the group's risk of social exclusion is higher than the national average, although only in France the relative risk factor appears to be higher than two. In two countries, France and Greece, one in five of the group's members are classified as being at high risk of social exclusion.

In the next Graph, 1.3, the reference persons of the members' households were unemployed in wave 1 . The evidence of the graph demonstrates very clearly that this is a high-risk group in all countries. In three of them - the N etherlands, Belgium and Germany - the group's risk of social exclusion is between five and six times higher than the national average and in six others the relevant factor is between 3 and 5 (Ireland, Luxembourg, the UK, Spain, Italy and France). On the contrary, in the two countries with the highest aggregate social exclusion scores, Portugal and Greece, the corresponding factor is substantially lower than $2^{2}$ For this reason it is interesting to

${ }^{21}$ This may be partly attributed to the large value of the denominator used for the calculation of the relative risk factor in these countries. 
turn our focus to the share of the group's members classified as being at high risk of social exclusion. In the UK over half of the group's members face a high risk of social exclusion, while the corresponding figures for Belgium and Ireland are around 35\% and for the rest of the countries, apart from Denmark, between $20 \%$ and $31 \%$. Only in Denmark, less than one in thirteen of the group's members faces a high risk of social exclusion. According to the evidence of Graph 1.6, in Ireland and Spain this group has the highest contribution to the aggregate risk of social exclusion in comparison with any other group, when the population is grouped according to the employment status of the reference person in wave 1. In Ireland the relevant contribution is $51.5 \%$, in Spain 37.3\% and in three other countries (Belgium, the UK and Germany) between $20 \%$ and $30 \%$. Relatively few of the group's members remained members of the group throughout the three first waves of the ECHP. In all the countries for which the numbers are sufficiently large to allow a proper examination (Spain, France, Greece, Ireland, Italy and the UK) the corresponding risk factors were higher sometimes substantially so - than those depicted in Graph 1.3. These results imply that labour market participation provides an extremely important safety net against social exclusion. N evertheless, as the case of Denmark points out, this is not likely to be the entire story.

The evidence of Graph 1.4 reveals considerable disparities regarding the risks of social exclusion of members of households whose reference persons was classified as 'Retired' across the EU. In two southern countries, Greece and Portugal, the group's risk of social exclusion is more than twice as high as the national average and around one third of the group's members are classified as being at high risk of social exclusion. On the contrary, in the Netherlands, Luxembourg and, particularly, Ireland this appears to be a low-risk group. In the rest of the countries under examination the share of the group classified as being at high risk of social exclusion does not differ substantially from the national average. The evidence of Graph 1.6 suggests that in Greece one in three and in Portugal one in four of the population members classified as being at high risk of social exclusion are members of this group.

\footnotetext{
22 In the case of the Netherlands, very few persons were classified as 'Retired' in the ECHP and this variable was reconstructed on the basis of the composition of the reference person's income (he/ she was classified as 'Retired' if over $50 \%$ of his/ her incomes were pensions).
} 
Graph 1.5 refers to a rather heterogeneous group of persons lumped together under the label 'Other inactive'. They are members of households whose reference person is inactive, although not retired - mostly house workers and students. In all countries the group's relative risk factors are high - reaching 6.97 and 6.43 in the cases of Denmark and Luxembourg, respectively. Factors higher than three are also recorded in the Netherlands, Germany, Belgium, the UK, France and Italy, while in all countries apart from Spain and the Netherlands over one in five (almost one in two in the UK) of the group's members face a high risk of social exclusion. According to Graph 1.6 in four countries (the Netherlands, UK, Germany and Ireland) over 30\% of those dassified as being at high risk of social exclusion are members of this group. In the first three of these countries the group's share among those classified as being at high risk of social exclusion is the highest among all groups formed when the population is divided according to the reference person's employment status in wave 1.

\subsection{Risk of social exclusion according to household type}

The next set of graphs, 2.1-2.5, reports evidence on the risk of social exclusion of population groups formed according to their household type in wave 1 . The first of these graphs, 2.1, refers to 'older households without children', that is, persons aged 65 or more living alone and couples without children where at least one of the partners is aged over 64 . The results are in line with the results of Graph 1.4. In most countries the group's risk of social exclusion is not considerably different from the national average. In Ireland, the Netherlands and Luxembourg they face a risk of social exclusion substantially lower than the national average, while in Portugal and, especially, Greece this risk is more than twice as high as the risk faced by the average population member. In fact, in Greece around $40 \%$ and in Portugal around 35\% of the group's members are classified as being at high risk of social exclusion, whereas in all other countries (apart from Italy and the UK) this proportion is lower than $10 \%$ - sometimes notably so. According to the evidence reported in Graph 2.6, a little over $30 \%$ in Greece and a little over $20 \%$ in Portugal of those dassified as being at high risk of social exclusion are members of this group. In no other country does the corresponding percentage exceed 15\%; moreover, in Luxembourg, the Netherlands and, particularly, Ireland the relevant figure is below $6 \%$. 
Graphs 2.1-2.5. Population members at high risk of social exclusion (Groups formed according to household type in wave 1)
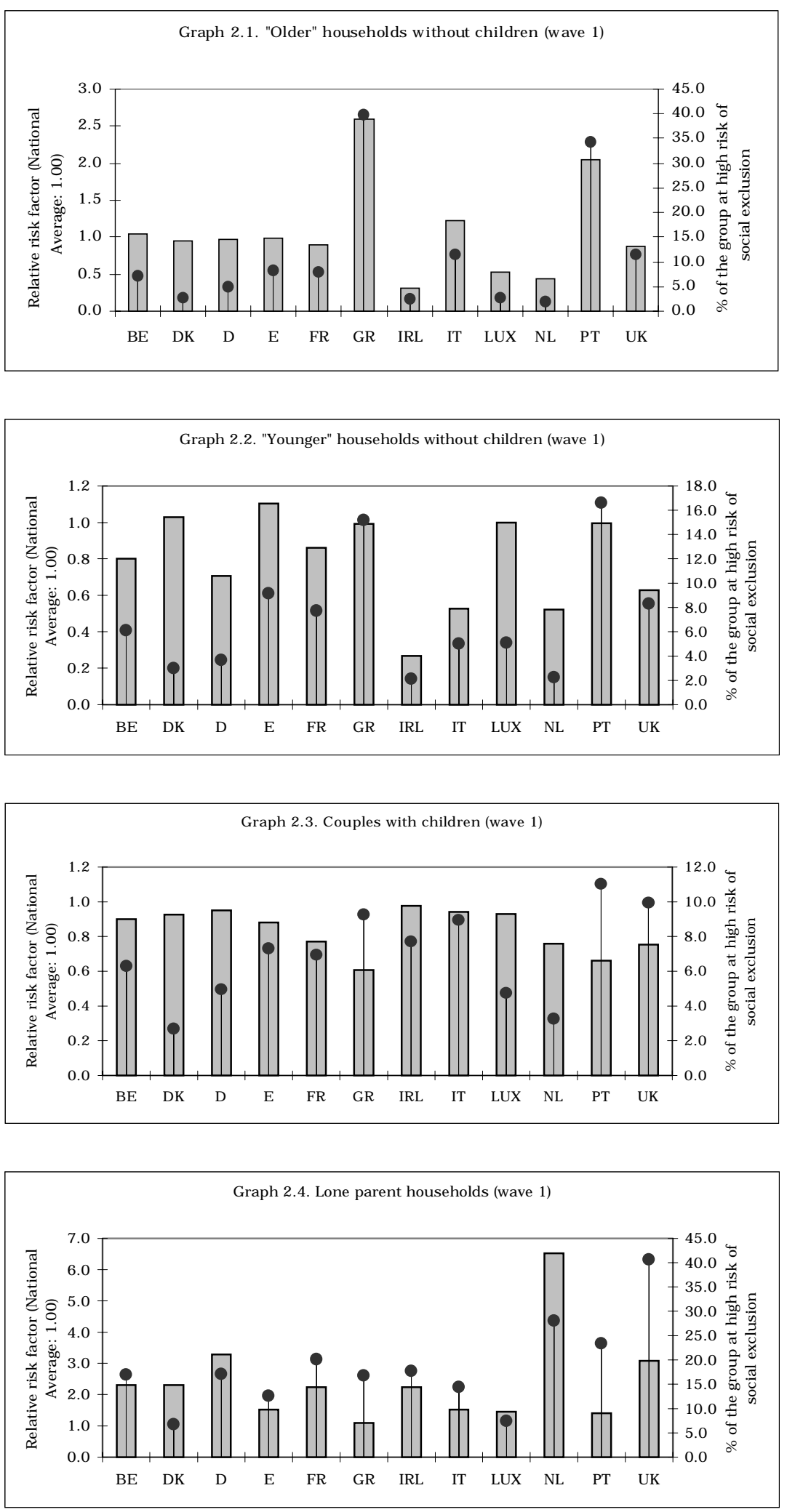


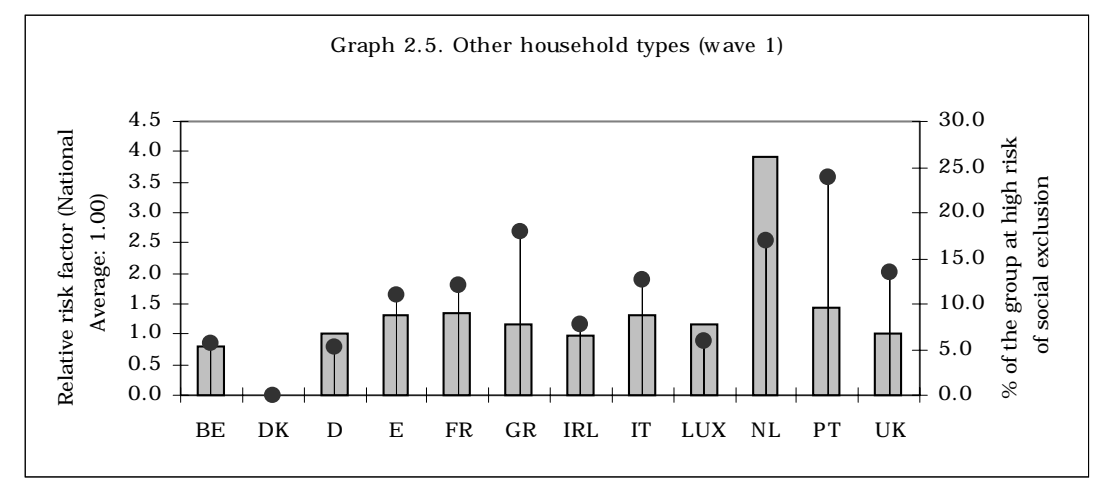

Graph 2.6 Composition of the group of people at high risk of social exclusion

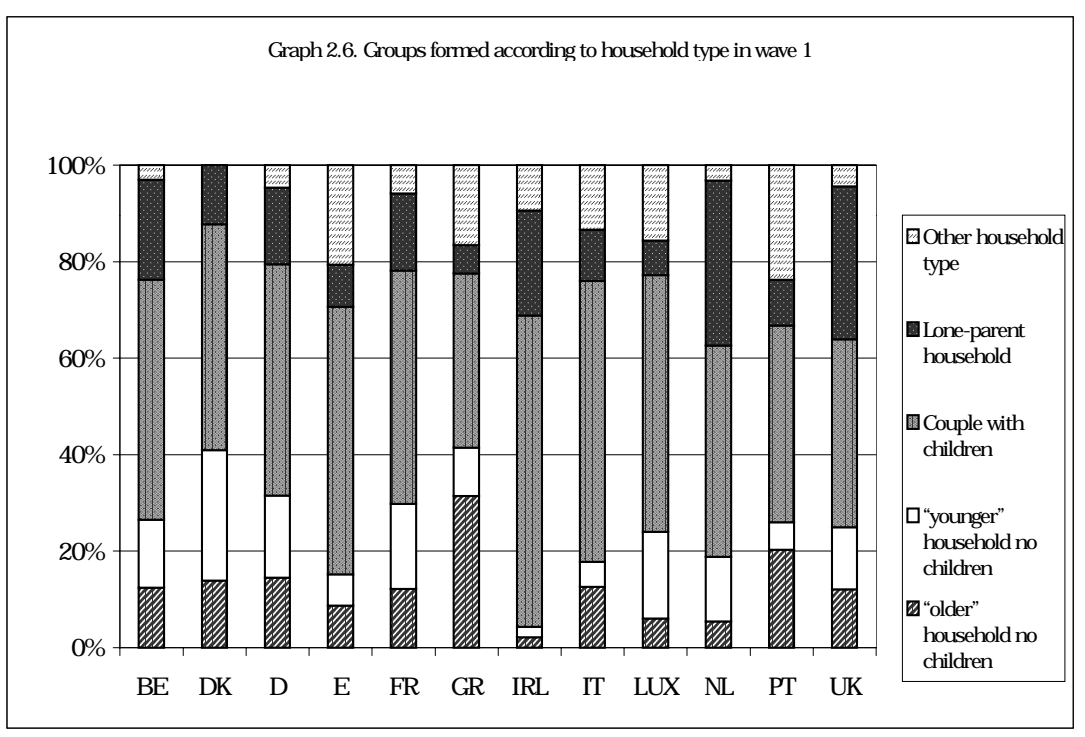

Graph 2.2 reports results for the group of 'younger households without children'; i.e. people aged below 65 living alone and couples without children where both partners are aged below 65. In most countries the risk of social exclusion of this group is similar to the national average. Very low risk factors are observed in Ireland, the N etherlands, Italy and, to a lesser extent, the UK and Germany.

Graph 2.3 shows that in no country are couples with dependent children a highrisk group. In those countries where the elderly face a high risk of exclusion (Greece

\footnotetext{
23 The estimates behind the charts shown in Graphs 2.1 and 2.2 might be sensitive to the economies of scale implied by the particular set of equivalence scales used in the analysis. Ceteris paribus, the use of equivalence scales implying higher (lower) household economies of scale would have resulted in more (fewer) members of one or two-member households being classified as poor and, consequently, facing a high risk of social exclusion. Taking into account that in all EU member-states the great majority of the elderly live either alone or with their spouses, to a large extent, this is al so true for the estimates reported below in Graphs 3.4 and 3.5. It should be noted that the results of Buhmann et al. (1988) show that the household economies of scale implied by the modified OECD equivalence scales that are used here lie somewhere in the middle in comparison with other sets of equivalence scales used in the literature.
} 
and Portugal) the group's relative risk factor is considerably lower than 1 , although they are the highest shares of the group's members at high risk of social exclusion in these countries and the UK. Since in all countries most people live in such households (population shares between 51-66\%) it is not surprising that in all countries this is the group with the highest share among population members facing high risk of social exclusion (Graph 2.6). Yet, the corresponding figures range from 35-40\% (Greece and the UK) to almost 65\% (Ireland).

Graph 2.4 shows the risk of social exclusion of members of lone parent households. In all countries the group's risk of social exclusion is higher than the national average, yet large cross-country differences are evident. In Greece the group's risk of social exclusion is slightly higher than the national average and the corresponding differences are not large in the cases of Portugal, Luxembourg, Spain and Italy either. In the other countries - notably in the N etherlands, and, to a lesser extent, Germany and the UK - the group's risk of social exclusion is substantially higher than the national average. The proportion of the group that is classified as being at high risk of social exclusion in the UK exceeds $40 \%$ and lies between $20-30 \%$ in the Netherlands, Portugal and France. These factors and considerable crosscountry differences in the group's population share, show that in the Netherlands and the UK over $30 \%$ of those classified as being at high risk of social exclusion live in lone parent households (Graph 2.6). The corresponding shares are below $10 \%$ for Portugal, Spain, Luxembourg and, particularly, Greece.

The group of members of "Other household types" (Graph 2.5) is rather heterogeneous as it consists of the members of all other household types - mostly three-generation households in the South and households of unrelated individuals in the North. A part from Denmark (zero risk of social exclusion) and the N etherlands (high risk of social exclusion in relative terms), in most other countries the group's risk of social exclusion is close to the national average.

\subsection{Risk of social exclusion according to age group}

In the next graphs the population groups are formed on the basis of attributes of the individual rather than the household. In Graphs 3.1-3.5 the grouping factor is the individual's age. The evidence of Graph 3.1 is in line with the findings of Immervol et al. (2001) and demonstrates that in all but one of the countries under examination children (persons aged up to 16) are at a higher risk of social exclusion than the 
average population member. The only exception to this rule is Greece, where the corresponding risk is considerably lower than the national average. In five countries (Ireland, the UK, Netherlands, Luxembourg and Germany) the relative risk of children to be in the group of persons at high risk of social exclusion is over $50 \%$ higher than the national average. Moreover, in the case of the UK over one in five children faces a high risk of social exclusion while the evidence of Graph 3.6 shows that in Ireland almost half of those facing a high risk of social exclusion are below 17. The corresponding figures for the UK, the Netherlands and Luxembourg are 35\%40\% whereas, at the other end, the Greek figure is just above $13 \%$. 2

The picture emerging from Graph 3.2 regarding young adults (persons aged 1724 ) is rather mixed. In most countries, the group's risk of social exclusion fluctuates around the national average. There are two exceptions towards higher relative risk (the Netherlands and, especially, Denmark) and two in the opposite direction (Portugal and, particularly, Ireland).

Graphs 3.1-3.5. Population members at high risk of social exclusion (Groups formed according to the individual's age in wave 1)

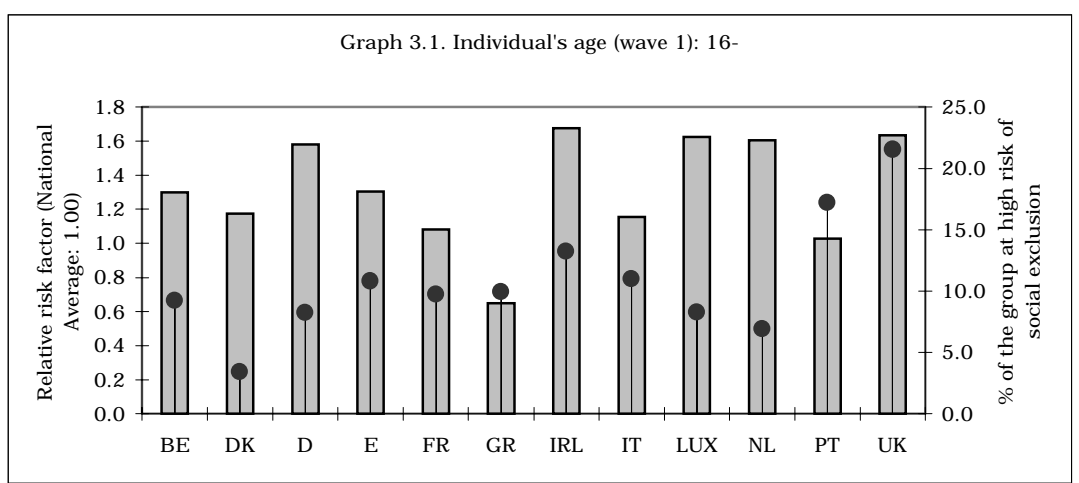

${ }^{24}$ These estimates might be sensitive to the economies of scale implied by the particular set of equivalence scales for the cost of children vis-à-vis the cost of adults in the analysis. Other things being equal, the use of equivalence scales implying lower (higher) needs of children in comparison with the needs of adults would have led to fewer (more) children being classified as poor and facing a high risk of social exclusion. The same applies to Graphs 2.3 and 2.4. 

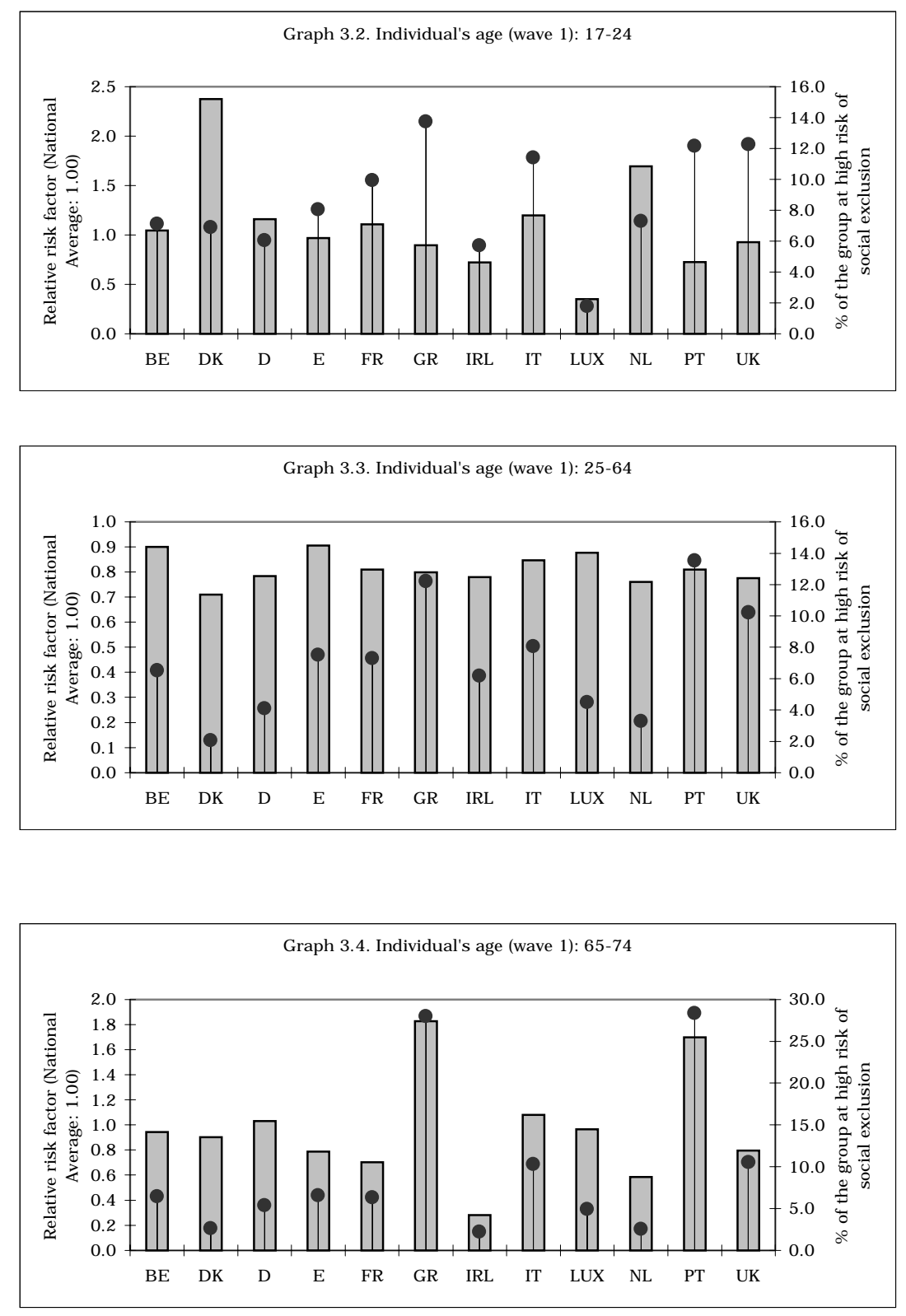

N ote: $65+$ for the case of Germany

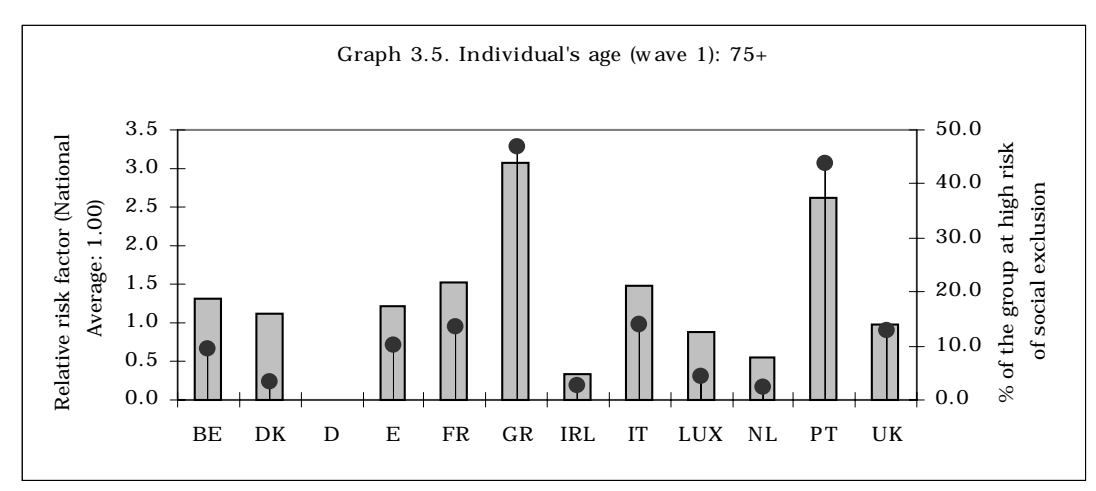


Graph 3.6. Composition of the group of persons at high risk of social exclusion

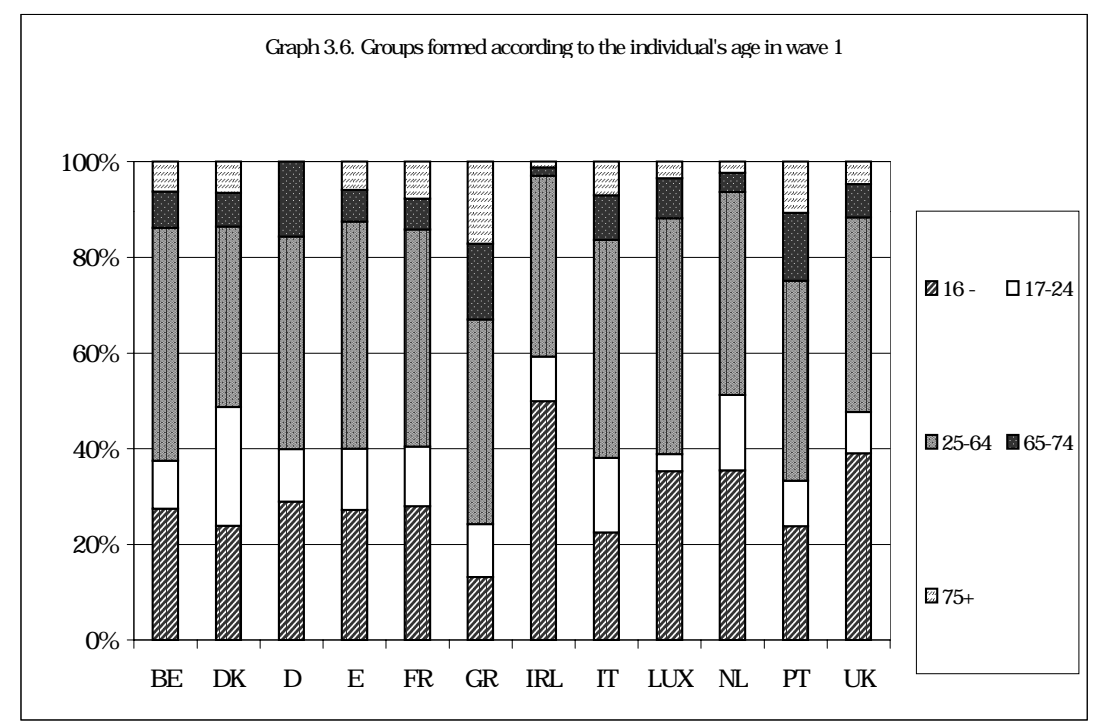

N ote: $65+$ for Germany

In line with what could be anticipated, the evidence of the next graph, 3.3, reveals that in all countries persons aged 25-64 face a lower risk of social exclusion than the rest of the population. Nevertheless, since in all countries this is the largest age group - in all countries apart from Ireland the population share of the group exceeds $50 \%$ the evidence of Graph 3.6 demonstrates that in all countries, apart from Ireland, this is the age group with the highest share among those at high risk of social exclusion.

The next two graphs, 3.4 and 3.5, show that in most countries under examination, firstly, the risk of social exclusion of the elderly (people over 64) does not differ very much from that of the rest of the population and, secondly, those aged over 74 usually face a higher risk of social exclusion than those aged 65-74. In line with the evidence of Graph 2.1, there are some strong exceptions to this rule. In Portugal and, especially, Greece the elderly and, particularly those aged over 74 face a risk of social exclusion that is substantially higher than the national average. In both countries around $45 \%$ of those aged over 74 are classified as facing a high risk of social exclusion. In addition, the picture emerging from Graph 3.6 suggests that in Greece around one third and in Portugal around one quarter of those at high risk of social exclusion are aged over 64. At the other extreme, in the Netherlands and, particularly, in Ireland the risk of social exclusion of the senior citizens appears to be considerably lower than that of the average population member.

24 In the case of Germany the ECHP data do not allow a disaggregation of the group of persons aged over 64 . 


\subsection{Risk of social exclusion according to the individual's employment status}

For the purposes of the last set of graphs, 4.1-4.6, each country's population is grouped according to the individual's rather than the household reference person's employment status. However, there are some differences between the classifications used in these graphs and those used in Graphs 1.1-1.5. The ECHP contains information on both the individual's employment record as well as self-reported information on the security of his or her current employment position. Using this information we constructed a third group of employed persons called 'precariously employed'. These are individuals who were employed in the first wave of the ECHP but during the previous five years had either at least two unemployment spells or at least one unemployment spell longer than one year, and, in addition, reported that they feel 'extremely' or 'very' insecure in their current employment.55 Apart from them, we formed three more groups of labour market participants: persons who were employed full-time (but not 'precariously employed'); persons who were employed part-time (but not 'precariously employed'); and persons who were unemployed in the first wave of the ECHP.

Furthermore, the group of inactive persons was subdivided into two groups. The first group was formed by 'discouraged and constrained workers'. 'Discouraged workers' are those who reported that they left the labour market because they believed that there was no proper job for them. 'Constrained workers' are those who were inactive in the first wave of the ECHP and reported that would have liked to have a job but were not seeking employment because of housework or looking after children or other people. In all countries the overwhelming majority of the group of discouraged and constrained workers are females. The second group of inactive people includes all other inactive persons ('other inactive').

25These are the two lowest categories in a 1 to 6 categorisation of replies to the question: ' $\mathrm{How}$ satisfied are you with your present job or business in terms of job security?' 
Graphs 4.1-4.6. Population members at high risk of social exclusion (Groups formed according to the employment status of the population member in wave 1)
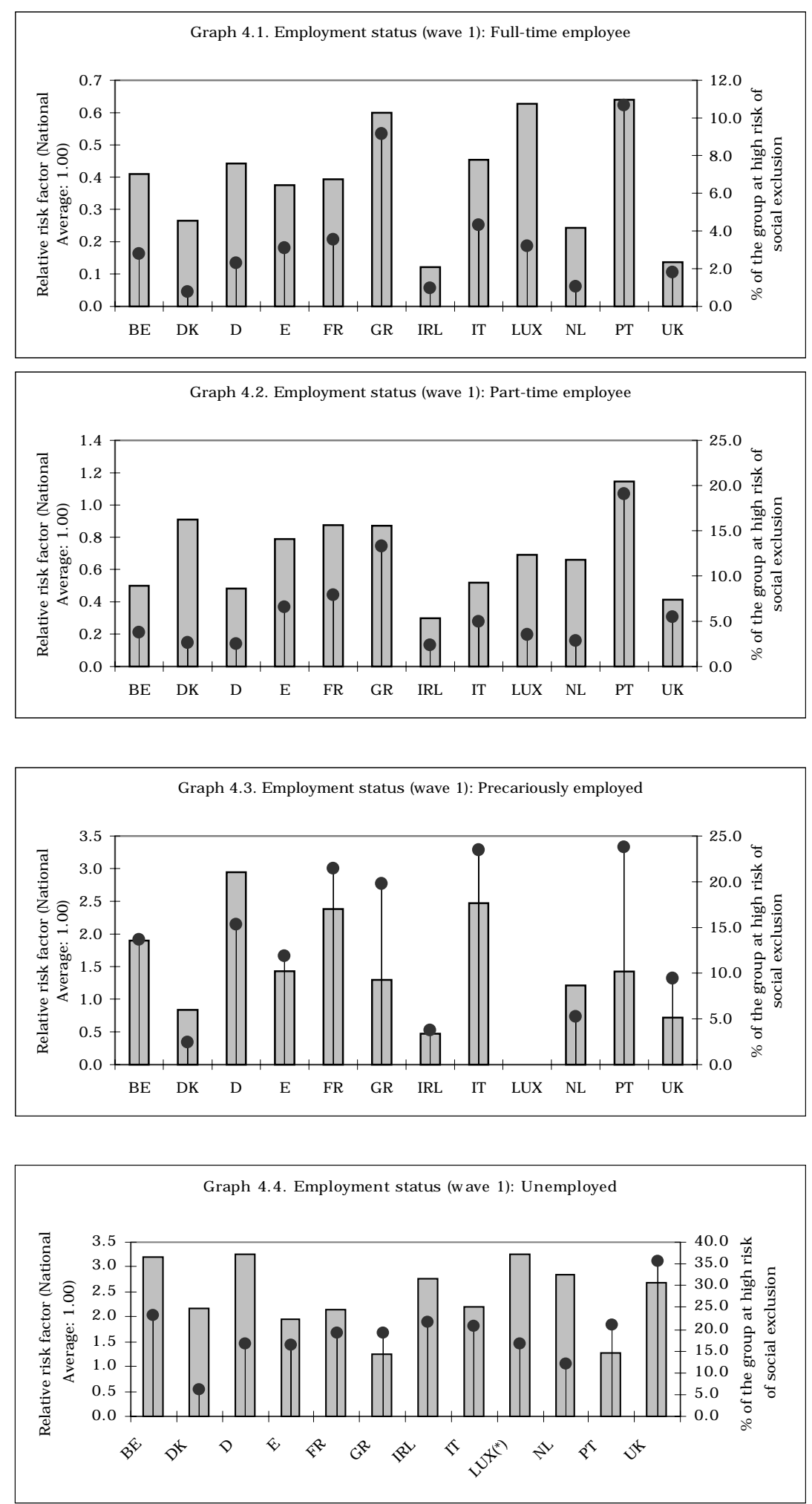

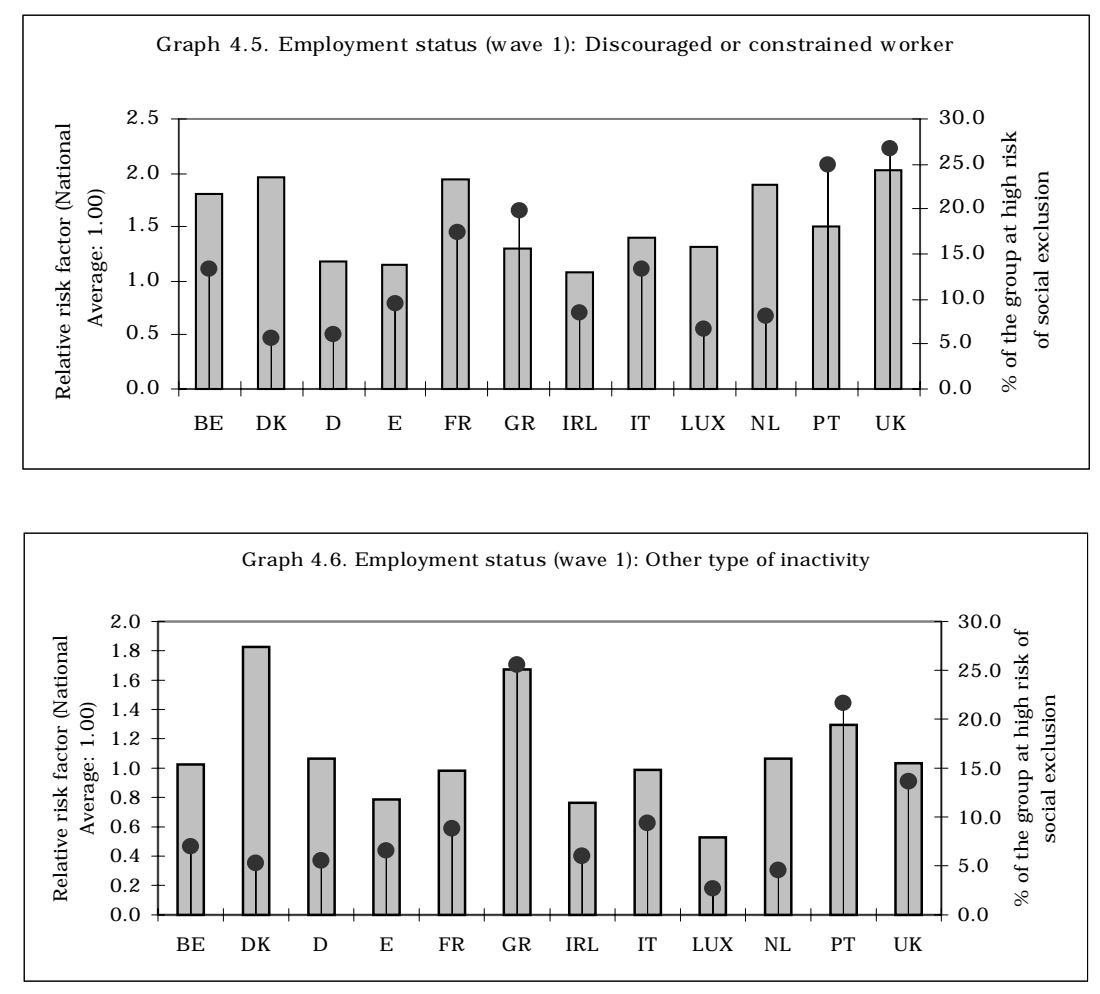

Graph 4.6. Composition of the group of persons at high risk of social exclusion

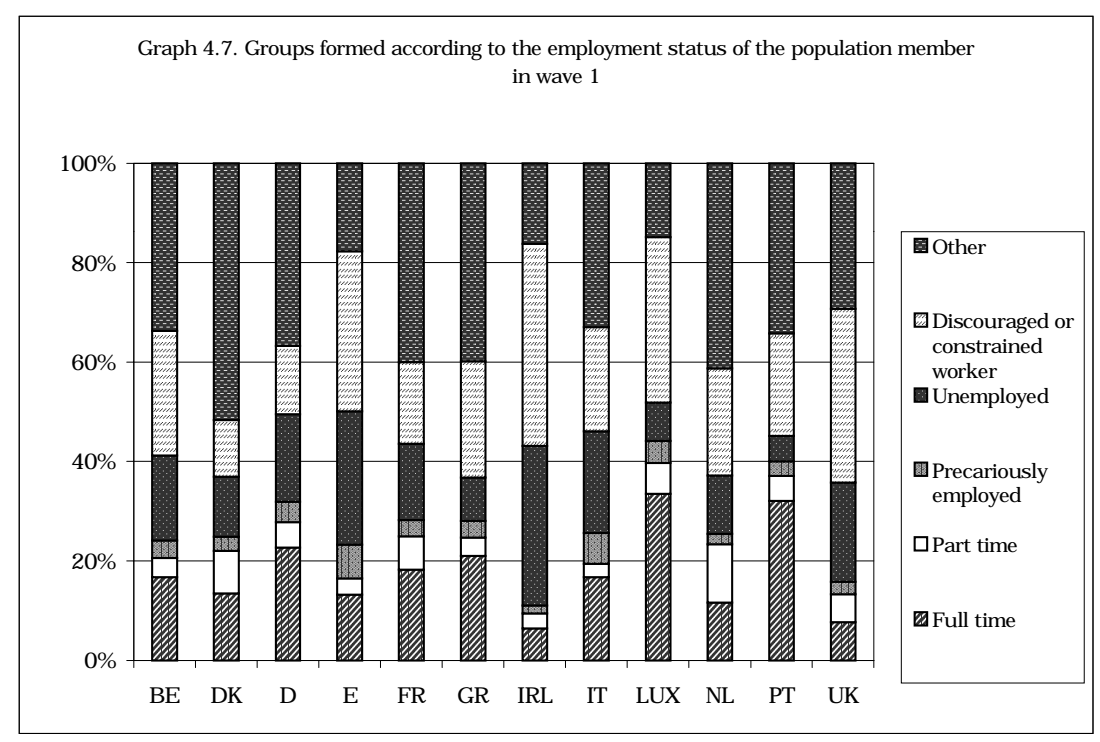

Graph 4.1 shows that in all countries the risk of social exclusion of population members who were employed full-time in wave 1 is lower than the risk of social exclusion faced by members of households headed by persons employed full-time in wave 1 reported in Graph 1.1 and considerably lower than the corresponding risk faced by the rest of the population. In fact, when we restricted the group to those who were employed full-time in all three waves, the results were even more 
impressive. Even though, on average, one in three persons belonged to this group, only one in nine of those classified as being at high risk of social exclusion was found to be a member of the group. Nevertheless, there are considerable cross-country variations (Graph 4.1). In Ireland and the UK the group's relative risk factor is below 0.15 while in Greece, Luxembourg and Portugal it is over 0.60 . Thus, both the share of the group classified as being at high risk of social exclusion and the corresponding contributions to the aggregate risk of social exclusion vary enormously across countries (according to Graph 4.7, the latter ranges from less than 5\% in Ireland to almost 32\% in Portugal).

Part-time employment is far more common in northern than in southern EU member states and, in recent years, there has been a lot of debate as to whether parttime employment is voluntary or involuntary. The evidence of Graph 4.2 suggests that in all countries under consideration, apart from Portugal, the risk of social exclusion of those who were classified as employed part-time in wave 1 (and were not precariously employed) was lower than the national average. Moreover, comparison of the estimates behind Graphs 1.2 and 4.2 suggests that in all countries apart from Luxembourg and the Netherlands the risk of social exclusion of persons employed part-time is lower than the corresponding risk of persons living in households headed by persons employed part-time. This may be due to the fact that many part-time workers are members of households containing members of low-risk groups, such as persons employed full-time (many part-time workers are spouses of persons employed full-time). Once again, considerable variations are observed regarding relative risk ratios across countries. As a consequence of this variation and, particularly, differences in population shares, the contribution of the part-timers to the aggregate risk of social exclusion reported in Graph 4.7 varies between $3 \%$ in Spain and $10 \%$ in the Netherlands.

Using the above definition, the share of the precariously employed in the entire population is rather small. It varies from less than $0.5 \%$ in low-unemployment Luxembourg to $4.4 \%$ in high-unemployment Spain.26) Graph 4.3 -shows that wide variation can be observed across EU member states regarding the group's relative risk of social exclusion. In most countries the group's members face a higher risk of social exclusion than the average population member. In fact, in Germany, France

26 On average around one in twenty employed population members belong to this group, although the ratio in Spain is almost one in nine. 
and Italy the group's risk is more than twice as high as that of the average population member. On the contrary, in Denmark, the UK and, particularly, Ireland the group's relative risk factor is lower than one.

Comparison of Graphs 1.3 and 4.4 demonstrates that the risk of social exclusion faced by unemployed persons is higher than that of the average population member but, in all countries, it is lower than the risk faced by members of households headed by unemployed persons. Cross-country differences similar to those reported in Graph 1.3 are also reported in Graph 4.4. In Greece and Portugal the risk of social exclusion of unemployed persons is higher than the national average, but not substantially so. At the other end, the risk of social exclusion of unemployed persons in Germany, Luxembourg, Belgium, the Netherlands, Ireland and the UK is between 2.7 and 3.3 times higher than the national average. The combination of these differences with very large differences in the unemployment rates of the countries under examination, produces sizeable cross-country differences in the group's contribution to the aggregate risk of social exclusion in Graph 4.7, ranging from a little over $5 \%$ in Portugal to almost $25 \%$ in Spain.

As noted earlier, the group of discouraged and constrained workers consists mainly of females. The group's population share varies from $5.6 \%$ in Denmark to $27.4 \%$ in Ireland. In most countries its population share varies between $10 \%$ and $20 \%$. Shares higher than 20\% are recorded, apart from Ireland, in Spain and Luxembourg, while shares lower than 10\% are observed, apart from Denmark, in France and the Netherlands. Without a single exception, Graph 4.5 shows that in all countries under examination the group's risk of social exclusion is higher than the national average. In the UK and Portugal over one in four of the group's members faces a high risk of social exclusion, while in Greece the corresponding ratio approaches one in five. Mostly as a result of high population shares, the evidence of Graph 4.7 suggests that in four countries (Spain, Ireland, Luxembourg and the UK) the group of discouraged and constrained workers is the population group with the largest share among those facing a high risk of social exclusion, when the population is grouped according to the employment status of the individual.

Graph 4.6 reports results for the rather heterogeneous group of 'Other inactive' persons. In six countries the group's risk of social exclusion is higher than the national average and in six others it is lower. Nevertheless, in all countries this is the second largest group after the low-risk group of persons employed full-time. Mostly 
as a result of its large population share, Graph 4.7 points out that in eight of the twelve countries under consideration this is the group with the highest share among those facing high risk of social exclusion.

\section{Conclusions}

The paper attempted to provide a methodology for identifying population members at high risk of social exclusion using the data of the first three waves of the ECHP. According to this methodology, initially we identified persons deprived in particular fields (Income, Living Conditions, Necessities of Life, Social Relations), then proceeded to identify the extent of their cumulative disadvantage and, finally, we focused on those suffering from chronic cumulative disadvantage. It is this last group that we identified as persons at high risk of social exclusion. Using this approach on the ECHP data for 12 EU member states we found considerable cross-country variation in the aggregate risk of social exclusion. The highest levels of aggregate risk of social exclusion were observed in some southern countries (Portugal and Greece) and the UK and the lowest in northern and central European countries (Denmark, the N etherlands, Luxembourg and Germany).

In the next step, we turned our focus to population groups at high risk of social exclusion when the population is grouped according to the employment status of the household's reference person, household type, age group and employment situation of the individual. The results show that there are many qualitative similarities and quantitative differences across the EU. In almost all countries it was observed that the looser the links of the individual or the household with the labour market - in the form of unemployment, precarious employment or the existence of various barriers to labour market participation - the higher the risk of social exclusion in comparison with the rest of the population. However, the extent to which secure and uninterrupted employment provides a shield against social exclusion was found to vary a lot across countries. Moreover, in most countries substantial proportions of persons at high risk of social exclusion are, actually, employed or live in households where the reference person is employed (most of them in full-time jobs). Turning to similarities and differences across demographic groups, it was found that in almost all countries children are facing a higher risk of social exclusion than the rest of the population. To a large extent, this risk is accounted by the higher than average risk of social exclusion facing children living in loneparent households. The population 
share of persons living in lone-parent households varies a lot across the EU and although in all countries this group's relative risk of social exclusion is higher than average, it differs significantly across countries. At the other end of the demographic spectrum, older persons seem to face a risk of social exclusion substantially higher than average in only two southern countries (Greece and Portugal).

The paper did not aim to provide detailed policy prescriptions for the fight against social exclusion in Europe. Nevertheless, our results seem to lead to one important policy implication. The prevailing socio-economic arrangements across EU member-states seem to be quite different and determine both the aggregate risk of social exclusion and the structure of the population groups at high risk of social exclusion. As a result, one-size-fits-all policies aimed at fighting social exclusion in Europe are not likely to have a significant impact in all countries. Different, tailormade policies adapted to the local conditions in individual member states are likely to be necessary in order to reduce the risk of social exclusion in European societies substantially. This does not mean that particular member states cannot learn from each other. In fact, the role of the EU in this field may be crucial. 


\section{Appendix 1: ECHP Information used for the Construction of Deprivation Indicators in the Fields of Living Conditions and N ecessities of Life}

The information contained in the ECHP on hougenold amenities refers to the existence of the following amenities in the dwelling: 7

- A separate kitchen

- A bath or shower

- An indoor flushing toilet

- Hot running water

- Central heating or electric storage heaters

- A place to sit outside (e.g. terrace or garden)

The, self-reported, ECHP information on accommodation refers to the following problems:

- Shortage of space

- Noise from neighbours or outside

- Too dark, not enough light

- Lack of adequate heating facilities

- Leaky roof

- Damp walls, floors, foundation etc.

- Rot in window frames or floors

- Pollution, grime or other environmental problems caused by traffic or industry

- Vandalism or crime in the area

The information on enforced lack of durable goods concerns the following items: 29

- Car or van (available for private use)

- Colour TV

- Video recorder

- Microwave

- Dishwasher

- Telephone

- Second home (e.g. for vacation)

Likewise, the information related to the ability of the households to afford certain Necessities of Life is the following:

- Keep their homes adequately warm

${ }^{27}$ The wording of the relevant question in the ECHP is: 'Does the dwelling have the following amenities?'

${ }^{28}$ The wording of the relevant question in the ECHP is: 'Do you have any of the following problems with your accommodation?'

29 The wording of the relevant question in the ECHP is: 'For each item below, please indicate whether or not your household possesses it. If you do not have an item, please indicate whether you would like to have it but cannot afford it'.

30 The wording of the relevant question in the ECHP is: 'There are some things many people cannot afford even if they would like them. Can I just check whether your household can afford these, if you want them?' 
- Pay for a week's annual holiday away from home

- Replace a worn-our furniture

- Buy new, rather than second-hand, cl othes

- Eat meat, chicken or fish every second day

- Have friends or family for a drink or meal at least once a month 


\section{REFERENCES}

Atkinson A.B. (1998) "Social exclusion, poverty and unemployment", in A.B. Atkinson and J. Hills (eds) Exclusion, employment and opportunity, CASE Paper No 4, Centre for Analysis of Social Exclusion, LSE, London.

Berghman, J. (1995) "Social exclusion in Europe: policy context and analytical framework", in G. Room (ed.) Beyond the threshold: The measurement and analysis of social exclusion, Policy Press, Bristol.

Buhmann B., Rainwater L., Schmaus G. and Smeeding T. (1988) "Equivalence scales, well-being, inequality and poverty: Estimates across ten countries using the LIS database", Review of Income and W ealth, 34, pp. 115-142.

Burchardt T., Le Grand J. and Piachaud D. (1999) “Social Exclusion in Britain 19911995", Social Policy and A dministration 33, pp. 227-244.

Desai M. and Shah S. (1988) "An econometric approach to the measurement of poverty", Oxford Economic Papers 40, pp. 505-522.

Eurostat (1996) The European Community H ousehold Panel (ECH P): Survey methodology and implementation, Theme 3, Series E, Eurostat, Luxembourg.

Eurostat (1997) Income distribution in EU 12 - 1993, Statistics in Focus 6, Eurostat, Luxembourg.

Eurostat (1999) ECH P data quality, DOC.PAN 119/ 99, Eurostat, Luxembourg.

Hagenaars, A. J. M., de Vos, K. and Zaidi, M. A. (1994) Poverty statistics in the late 1980s: Research based on micro-data, Theme 3, Series C, Eurostat Luxembourg.

Immervoll H., Sutherland H. and de Vos K. (2001) "Child poverty and child benefits in the European Union", in K. Vleminckx and T. M. Smeeding (eds.), Child Well-being, Child Poverty and Child Policy in Modern Nations, Polity Press Bristol.

ISSAS (1990) Poverty in figures: Europe in the early 1980s, Theme 3, Series C, Eurostat, Luxembourg.

Jenkins S.P. (2000) "Modelling household income dynamics", Journal of Population Economics 13, pp. 529-567.

Lenoir R. (1974) Les Exclus, SEUIL, Paris.

Mayes D, Berghman J and Salais R. (2001) Social exclusion and European policy, Edward Elgar, Cheltenham.

Mejer, L. (1999). 'Statistics on Social Exclusion: The EU Methodological Approach'. Eurostat, Luxembourg (unpublished manuscript).

O'Higgins M. and Jenkins S.P. (1990) “Poverty in EC: Estimates for 1975, 1980 and 1985", in R. Teekens and B.M.S. van Praag (eds) A nalysing poverty in the European Community, Eurostat N ews Special Edition, Luxembourg.

Rodrigues C.F. (1999) "Income distribution and poverty in Portugal: 1994/ 95", Technical University of Lisbon, Department of Economics Discussion Paper 4/ 1999.

Room G. (1995) Beyond the threshold: The measurement and analysis of social exclusion, Policy Press, Bristol. 
Sen A.K. (1998) "Social exclusion and economic measurement", paper presented at the $25^{\text {th }}$ General Conference of the International Association for Research in Income and Wealth, Cambridge.

Sen A.K. (1999) Commodities and capabilities, Oxford University Press, Oxford.

Smeeding T. M., Saunders P., Coder J., Jenkins S., Fritzell J. Hagenaars A. J. M. Hauser R. and Wolfson M. (1993) "Poverty, inequality and living standard impacts across seven nations: the effects of non-cash subsidies for health, education and housing", R eview of Income and W ealth 39, pp. 229-256.

Townsend P. (1979) Poverty in the U nited Kingdom: A survey of household resources and standards of living, Penguin, Harmondsworth.

Tsakloglou and Papadopoulos (2001) "Poverty, material deprivation and multidimensional disadvantage during four life stages: Evidence from the ECHP", in C. Heady, M. Barnes, J. Millar, S. Middleton, P. Tsakloglou and F. Papadopoulos (eds) Poverty and social exclusion in Europe, Edward Elgar, Cheltenham.

Vleminx K. and Berghman J. (2001) "Social exclusion and the Welfare State: An overview of conceptual issues and policy implications" in Mayes D, Berghman J and Salais R. (eds) Social exclusion and European policy, Edward Elgar, Cheltenham. 


\section{IZA Discussion Papers}

No. Author(s)

378

379

380

381

382
D. Clark

R. Fahr

H. Antecol

D. A. Cobb-Clark

M. Sattinger

J. T. Addison

P. Teixeira

L. Goerke

D. Blau

E. Tekin

D. Acemoglu

J.-S. Pischke

A. Ichino

R. T. Riphahn

J. Wagner

C. Schnabel

A. Kölling

C. Grund

D. Sliwka

L. Farrell

M. A. Shields

T. Beissinger

H. Egger

T. Beissinger

J. T. Addison

P. Teixeira

P. Tsakloglou

F. Papadopoulos
Title

Area

Date

The Promise of Workplace Training for Non-

1

$10 / 01$ College-Bound Youth: Theory and Evidence from German Apprenticeship

The Sexual Harassment of Female Active-Duty

5

$10 / 01$

Personnel: Effects on Job Satisfaction and Intentions to Remain in the Military

A Kaldor Matching Model of Real Wage

7

$10 / 01$ Declines

The Economics of Employment Protection

3

$10 / 01$

Tax Evasion in a Unionised Economy

$11 / 01$

The Determinants and Consequences of Child

3

$11 / 01$

Care Subsidies for Single Mothers

Minimum Wages and On-the-Job Training

$11 / 01$

The Effect of Employment Protection on Worker

$11 / 01$ Effort: A Comparison of Absenteeism During and After Probation

Threshold Values in German Labor Law and Job

3

$11 / 01$

Dynamics in Small Firms: The Case of the

Disability Law

The Impact of Wage Increases on Job

Satisfaction - Empirical Evidence and

Theoretical Implications

Child Expenditure: The Role of Working

3

Mothers, Lone Parents, Sibling Composition and Household Provision

Dynamic Wage Bargaining if Benefits are Tied to Individual Wages

3

The Impact of Labor Market Reforms on Capital

Flows, Wages and Unemployment

2

Employment Adjustment in Portugal: Evidence

from Aggregate and Firm Data

Identifying Population Groups at High Risk of

Social Exclusion: Evidence from the ECHP
1

3
$11 / 01$

$11 / 01$

$11 / 01$

$11 / 01$

$11 / 01$

.

$11 / 01$ 